\title{
Valorization of snail shell (Hélixaspersa) from Tangier-Tetouan region (north of Morocco): an application to eliminate methylene blue
}

\author{
Ghizlane Erradi *, Farida El yousfi and Mostafa Stitou \\ Laboratory of Water, Research and Environmental Analysis, Department of Chemistry, Faculty of Sciences, \\ University Abdelmalek Essaâdi, B.P. 2121, Mhannech II, 93002 Tétouan, Morocco.
}

\begin{abstract}
Removal of industrial waste becomes increasingly critical for environmental protection. This study aims to search for effective and less expensive adsorbents in order to remove methylene blue (MB) commonly used in many industrial sectors. To this end, we experiment Helix aspersa snail shell as a biosorbent for the removal of MB. The raw snail shells were cleaned, smashed, and characterized afterwards using a scanning electron microscopy (SEM) coupled with an energy dispersive X-Ray analysis (EDX) and by X-ray diffraction. Different parameters were tested in order to identify the optimal conditions for the effective removal of MB. Our experimental results showed that, within the first ten minutes, a remarkable elimination of methylene blue dye reaching a percentage of $82 \%$, with the following optimal conditions; $3.5 \mathrm{~g}$ of the adsorbent, initial $\mathrm{MB}$ concentration of $20 \mathrm{mg} / \mathrm{L}$, the temperature of $15{ }^{\circ} \mathrm{C}$, and agitation of $250 \mathrm{rpm}$. This study showed that the use of snail shell waste has inevitably a positive impact on the protection of the environment, in particular, the purification of industrial effluents.
\end{abstract}

Key words: Snail shell; biosorbent; removal; dye; methylene blue.

\section{Introduction}

Dyes are widely used in many industrial sectors including textile, paper, leather, and food industry. Dyes represent enormous risks to human health and the environment. They cause serious problems due to their stability and low biodegradability 1 . Furthermore, once degraded, dyes generate mutagenic or carcinogenic byproducts even more toxic than the dyes themselves ${ }^{2}$.

Several research studies have investigated the toxic effects of dyes on human health. Among these dyes, methylene blue is capable of causing very harmful effects on living beings such as breathing difficulties, vomiting, diarrhea, and nausea ${ }^{3}$.

Recently, several treatment techniques have been developed ${ }^{4}$ such as coagulation/flocculation ${ }^{5}$, irradiation ${ }^{6}$, filtration 7 , photo-degradation by catalysis ${ }^{8}$, biological treatment ${ }^{9}$, and activated carbon adsorption ${ }^{10}$. The use of activated carbons has many disadvantages generally related to its regeneration difficulty and its relatively high cost ${ }^{11}$. For this reason, several studies focused on finding other low-cost adsorbent materials available locally and made from natural resources including Coriandrum sativum seeds ${ }^{12}$, orange sawdust ${ }^{13}$,

*Corresponding author: Ghizlane Erradi

Email address: erradighizlane@gmail.com

DOI: http://dx.doi.org/10.13171/mjc8219040804ge chitosan-coated diatomaceous earth to removal heavy metals $14,15,16$.

Nowadays, the reuse of shell waste (crab, mussels, snail eggs, oysters, etc.) becomes the focus of concern 17,18 . Given its wide range of applications ${ }^{19,20}$, these natural materials are known for their respect for the environment, their availability, recyclability, and low cost.

The snail shell belongs to the Mollusc (Gastropoda). Several studies have been carried out on the snail shell. The shells were used as a good substitute for commercial $\mathrm{CaCO} 3^{21,22}$, as a coagulant in the precipitation of the malachite green of the aquatic system ${ }^{23}$, or as a source of calcium for the preparation of hydroxyapatite ${ }^{24,25}$. It has as well considerable values in the cosmetics and medicinal fields 26,27 .

The choice of using snail shells is justified by the fact that the production of biomass is less expensive, it allows the valorization of local products, but also it is a safe method to eliminate wastewater pollutants particularly the dyes.

In this work, we studied an adsorbent based on snail shell (Hélix aspersa) collected from the region of Tangier-Tetouan (northern Morocco). We used this raw adsorbent for the removal of methylene blue

Received February 20, 2019 Accepted March 1, 2019

Published April 8, 2019 
dye in synthetic solutions. Different experimental parameters were optimized such as adsorbent mass, temperature, and agitation.

\section{Materials and methods}

\section{Experimental}

In the context of green chemistry, the snail shell sof Helix aspersa were recovered from a snail vendor, (the spicy snail is a traditional recipe very popular in Morocco), located in Tangier and Tetouan (northern Morocco). According to the various samples tested for snail shell, it was found in this study that it is possible to work with the snail shell in its raw state without any pre-treatment.

\section{Preparation of adsorbent}

These bio wastes were first washed with tap water to remove surface impurities. Then, it was dried at $110{ }^{\circ} \mathrm{C}$ in the oven for 24 hours. Subsequently, they were crushed and sieved to obtain uniform particles. The particles size retained have a diameter between 0.20 and $0.80 \mathrm{~mm}$. The shell powder is packaged in small boxes and stored in a desiccator.

(Picture.1)
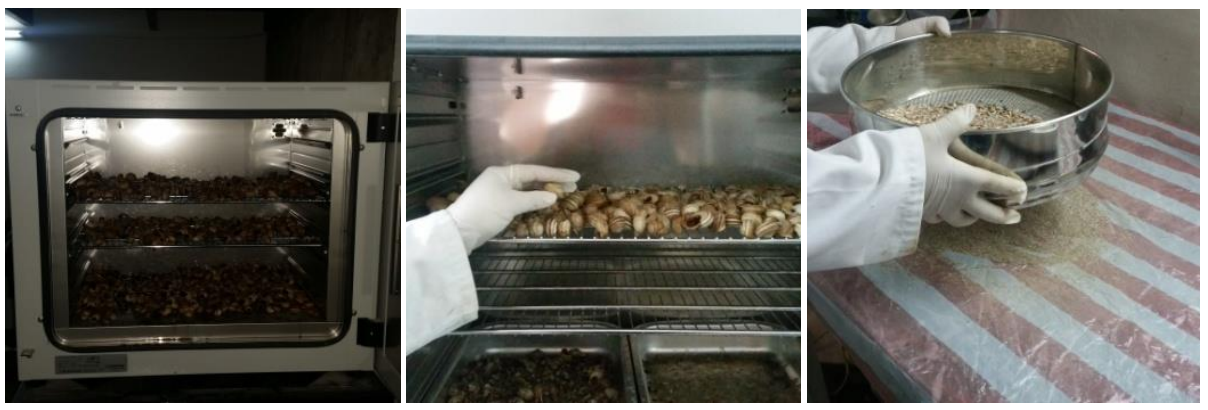

Picture 1: the stages of adsorbent preparation

\section{Methylene blue}

Methylene blue is a cationic dye of empirical formula: $\mathrm{C}_{16} \mathrm{H}_{18} \mathrm{ClN}_{3} \mathrm{~S}$ (FIG. 1).<smiles>CN(C)c1ccc2nc3ccc(=[N+](C)C)cc-3sc2c1</smiles>

Figure 1. Chemical Structure of Methylene Blue ${ }^{27}$

Its molar mass is $319.852 \mathrm{~g} / \mathrm{mol}$. It is soluble in water $\left(50 \mathrm{~g} / \mathrm{L}\right.$ at $\left.20{ }^{\circ} \mathrm{C}\right)$ and slightly in ethanol $(10$ $\mathrm{g} / \mathrm{L}$ at $\left.20^{\circ} \mathrm{C}\right)$. This dye is chosen as a representative model for medium-sized organic pollutants ${ }^{27}$. The used solutions are obtained by dissolving one gram of the methylene blue powder in one litter of distilled water.

\section{Analysis method}

The adsorption experiments were carried out by stirring $1 \mathrm{~g}$ of the snail shell-based biomass that prepared with $100 \mathrm{~mL}$ of the synthetic methylene blue (MB) solution in an orbital shaker (IKAKScontrol $4000 \mathrm{I}$ ), controlling the temperature and agitation.

Samples were taken every 10 min within $60 \mathrm{~min}$, and the suspensions were filtered through $0.45 \mu \mathrm{m}$

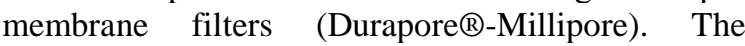
measurements of $\mathrm{MB}$ concentrations are made by UV-V is spectrophotometer (Varian Cary ${ }^{\circledR}$ Type 50 $\mathrm{UV}-\mathrm{Vis})$ at a maximum wavelength of $662 \mathrm{~nm}$. MB adsorption at equilibrium $\mathrm{q}_{\mathrm{e}}(\mathrm{mg} / \mathrm{g})$ and percent removals (\% removal) were calculated using the equations (1) and (2), respectively:

$$
Q_{a d s}=\frac{\left(C_{0}-C_{e q}\right)}{m} * \mathbf{V}
$$

The yield of adsorption:

$\operatorname{Yield}(\%)=100 * \frac{\left(C_{0}-C_{e q}\right)}{C_{0}}$

$\mathbf{Q}_{a d s}:$ adsorbed amount in $\mathrm{mg} / \mathrm{g}$;

$\mathbf{C}_{\mathbf{0}}$ : initial concentration of methylene blue in $\mathrm{mg} / \mathrm{L}$;

$\mathrm{C}$ : equilibrium concentration of methylene blue in $\mathrm{mg} / \mathrm{L}$;

$\mathbf{V}$ : volume of solution in $\mathrm{mL}$;

$\mathbf{m}$ : mass of biomass in $\mathrm{g}$.

\section{Characterization of the shell}

The characterization of the snail shell is an important analysis for understanding the behaviour or mechanism of MB elimination. The samples were characterized by the following two methods:

a- The morphology of the snail shell powder was observed using a scanning electron microscopy "Hirox scanning electron microscopy (SEM)"coupled with an Energy Dispersive X-ray analysis system(EDX). The images of the microstructure were obtained with a maximum acceleration voltage of $20 \mathrm{Kv}$.

b- X-Ray diffraction (XRD), the device used is coupled with diffractometer PHILIPS PW 1710. K $\alpha$ radiation of cooper $(\lambda=1.5406 \AA)$ was used. 


\section{Results and Discussions}

\section{Characterization by scanning electron microscopy (SEM)}

The observation of the samples by scanning electron microscopy (SEM) allowed us to visualize the morphology of the biomass prepared with snail shell (Figure 2).

The shell of mollusk is generally composed of limestone composed of $95 \%$ calcite and calcium carbonate ${ }^{28}$.
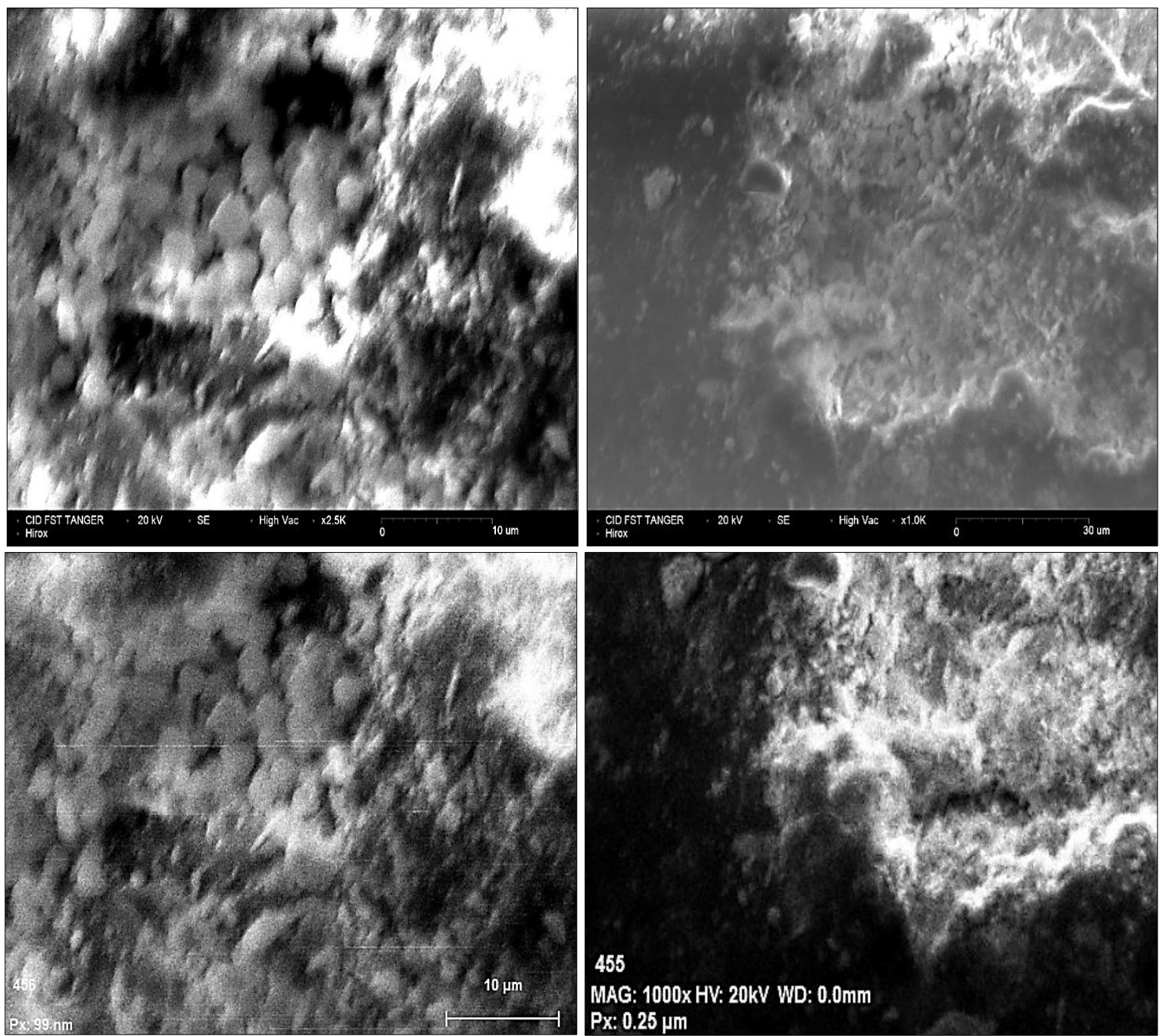

Figure 2. Scanning electron micrographs of the raw snail shell at different resolutions

Figure 2 shows that the shells structure of our sample has a granular morphology. According to previous works ${ }^{29}$, this arrangement is called microstructure, and may be present mainly in trigonal polymorphic calcite, or may be present in aragonite, orthorhombic polymorph of $\mathrm{CaCO} 3$. Both elements (calcite and aragonite) have an identical chemical composition. This microstructure can be, according to its internal order, prismatic or pearled, lamellar or homogeneous and foliated ${ }^{29}$.

In our opinion, and according to Figure 2, we believe that our sample has a pearlescent microstructure. To confirm this result; we performed an X-ray diffraction analysis.

The elemental composition of the snail shell is illustrated by the EDX spectrum in Figure 3 .
According to the EDX microanalysis, the main elements are calcium, oxygen and carbon, with weight percentages are respectively $50.59 \%$, $35.27 \%$, and $14.04 \%$. These data are grouped in Table 1.

Table 1. EDX Elemental Analysis (Mass and Atomic Percentage of Snail Shell).

\begin{tabular}{lcc}
\hline Elements & Weight \% & \% Atom \\
\hline Calcium & 50.59 & 27.21 \\
\hline Carbon & 14.04 & 25.19 \\
\hline Oxygen & 35.27 & 47.52 \\
\hline Silicon & 0.10 & 0.08 \\
\hline Total & 100.00 & 100.00
\end{tabular}




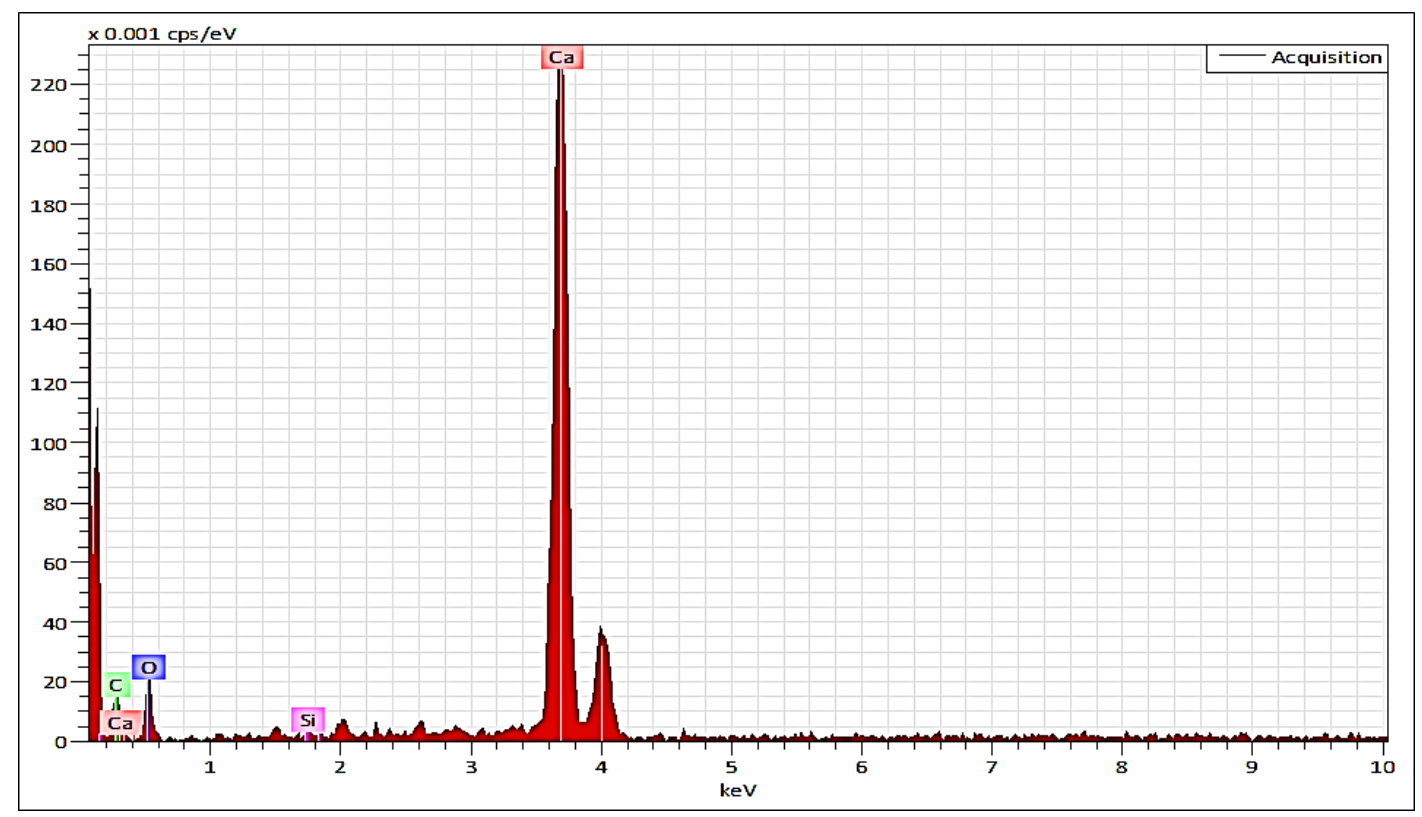

Figure 3. Representation of the energy dispersive X-Ray peaks (EDX) of the raw shell.

\section{X-Ray Diffraction (XRD)}

The X-ray diffraction analysis results of the raw shell are presented in Figure 4. Table 2 reports the crystallographic parameters of the raw shell. The latter crystallizes in a hexagonal system. Having a constant lattice orthorhombic crystal system, $\mathrm{a}=4.940 \AA, \mathrm{b}=7.940 \AA, \mathrm{c}=5.720 \AA$ and unit cell volume $\mathrm{V}=224.36 \AA$. By comparing values a, b, and $c$ of this biomass by those reported in the literature, it is suggested that the crystalline phase present in the shell is aragonite. These results confirm that the presence of aragonite in the shells is in agreement with the bibliographic works ${ }^{28}$. We can agree that the shell used in this study is composed mainly of polygonal aragonite crystals. X-ray diffraction was used to confirm the microstructure of our sample.
Table 2. Crystallographic parameters of the raw shell.

\begin{tabular}{ll}
\hline Formula & $\mathrm{CaCO}_{3}$ \\
\hline Name & Calcium Carbonate \\
\hline Name(mineral) & Aragonite \\
\hline Name(commun) & ${ }^{\mathrm{Y}-\mathrm{CaCO}_{3}}$ \\
\hline Lattice & Orthorhombic \\
\hline Mol.weight & 100.09 \\
\hline Volume[CD] & 224.36 \\
\hline Dm & 2.94 \\
\hline $\mathrm{I} / \mathrm{Icor}$ & -1.000 \\
\hline $\mathrm{A}$ & 4.940 \\
\hline $\mathrm{B}$ & 7.940 \\
\hline $\mathrm{C}$ & 5.720 \\
\hline $\boldsymbol{a} / \boldsymbol{b}$ & 0.62217 \\
\hline $\boldsymbol{c} / \boldsymbol{b}$ & 0.72040 \\
\hline
\end{tabular}

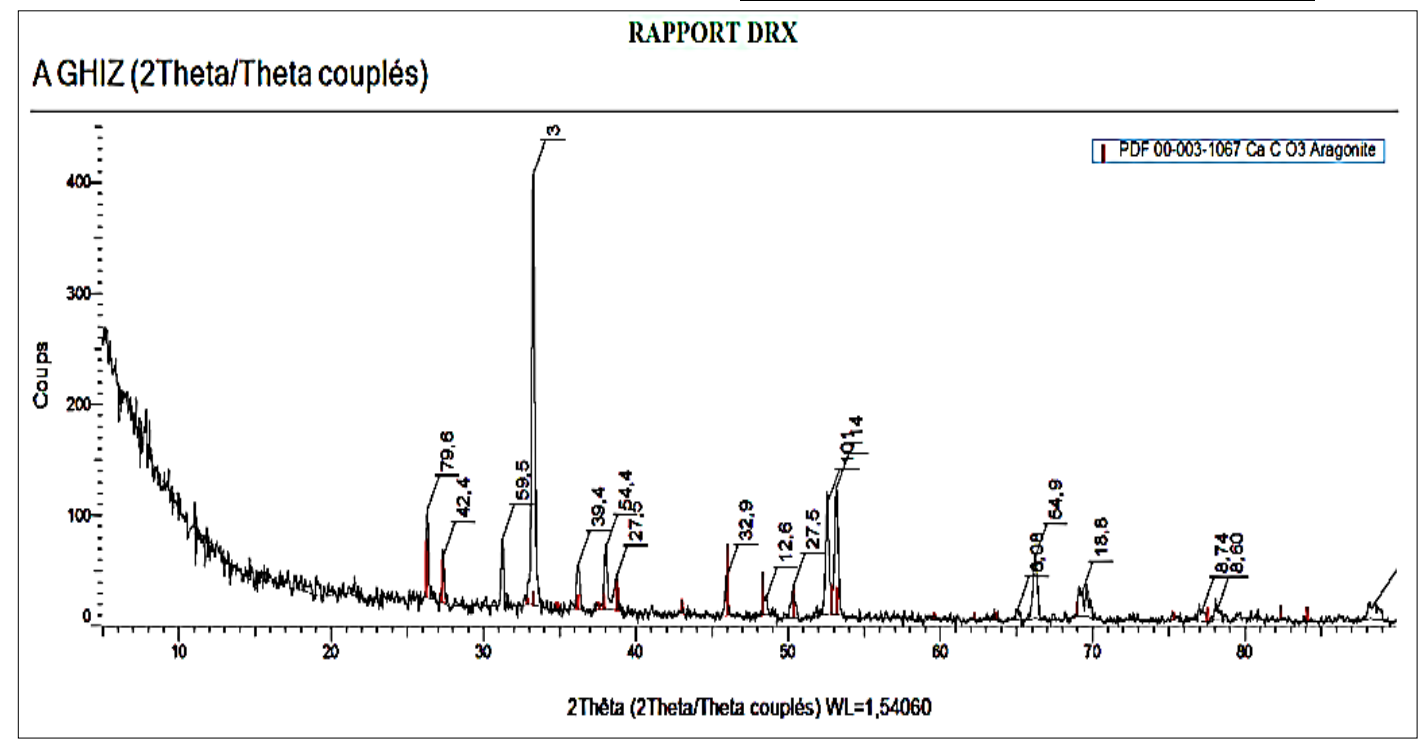

Figure 4. X-ray diffractogram of the raw snail shell used shell

Adsorption test of methylene blue by a snail

\section{The choice of samples}

In order to evaluate the optimal adsorption capacity of methylene blue by the snail shell, a series 
of samples was prepared by varying the mode, time, and heating shelf (Table 3).

Table 3. The different samples tested for the snail shell.

\begin{tabular}{|l|l|l|l|l|l|l|l|l|}
\hline Samples $\left(\mathrm{T}^{\circ}\right)$ & \multicolumn{5}{|c|}{$300^{\circ} \mathrm{C} / \mathrm{h}$} & \multicolumn{2}{c|}{$400^{\circ} \mathrm{C} / \mathrm{h}$} & $0^{\circ}(\mathrm{raw})$ \\
\hline $\begin{array}{l}\text { Time spent in the } \\
\text { oven }(\mathrm{h})\end{array}$ & $1 \mathrm{~h}$ & $2 \mathrm{~h}$ & $3 \mathrm{~h}$ & $4 \mathrm{~h}$ & $24 \mathrm{~h}$ & $48 \mathrm{~h}$ & $24 \mathrm{~h}$ & $0 \mathrm{~h}$ \\
\hline
\end{tabular}

\section{Adsorption test}

According to Table 3, a series of experiments were conducted using $100 \mathrm{~mL}$ of the $20 \mathrm{mg} / \mathrm{L}$ methylene blue solution, to which different samples of the activated and raw shells were added. The objective of this experiment is to optimize the elimination rate in order to obtain efficient adsorption of methylene blue using the raw and activated shell at a different temperature.

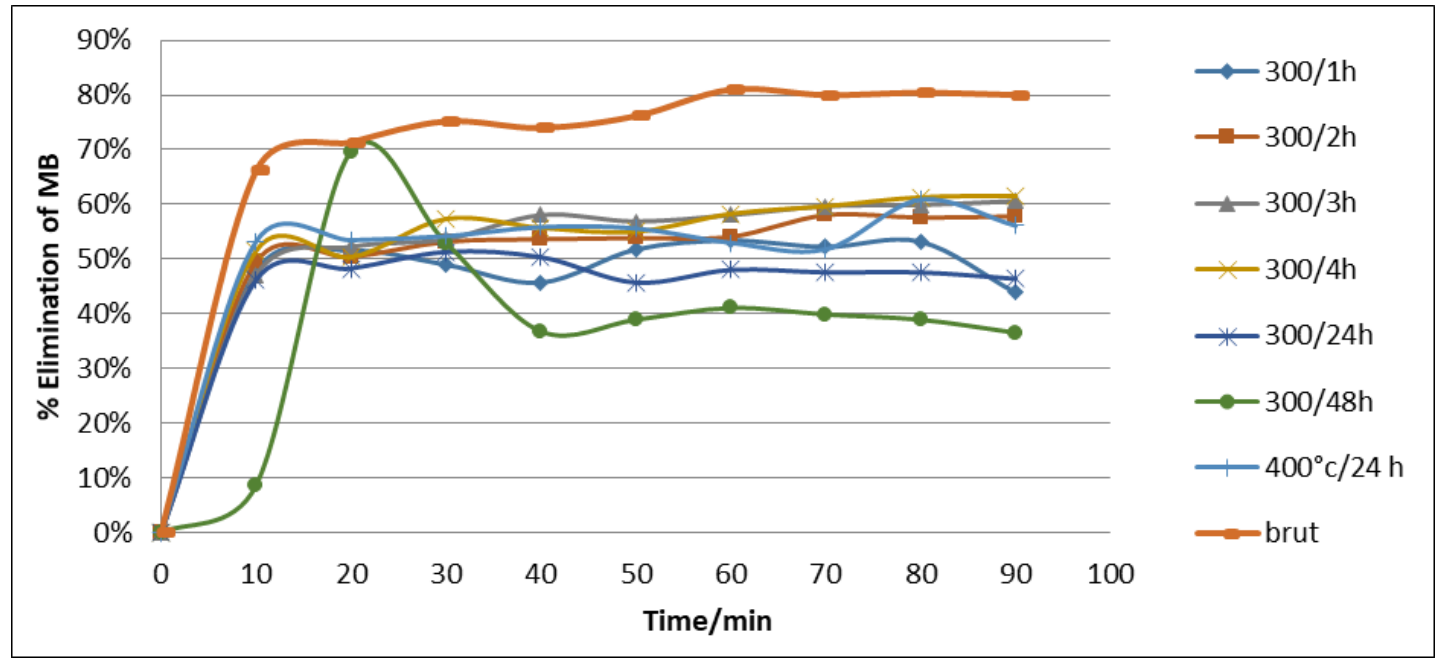

Figure 5. Adsorption test samples of raw and activated snail shells on the adsorption of MB dye.

Figure 5 shows that raw snail shine staining rates are higher compared to those obtained by adsorption on activated shells. Results show that the temperature of shell activation has a negative influence on the adsorption capacity of MB. This result can be due to the nature of the interactions of different samples with MB.
For economic reasons, the subsequent study of the MB dye adsorption process will be performed using raw snail shells without any prior treatment, and look for the optimization of several experimental parameters.

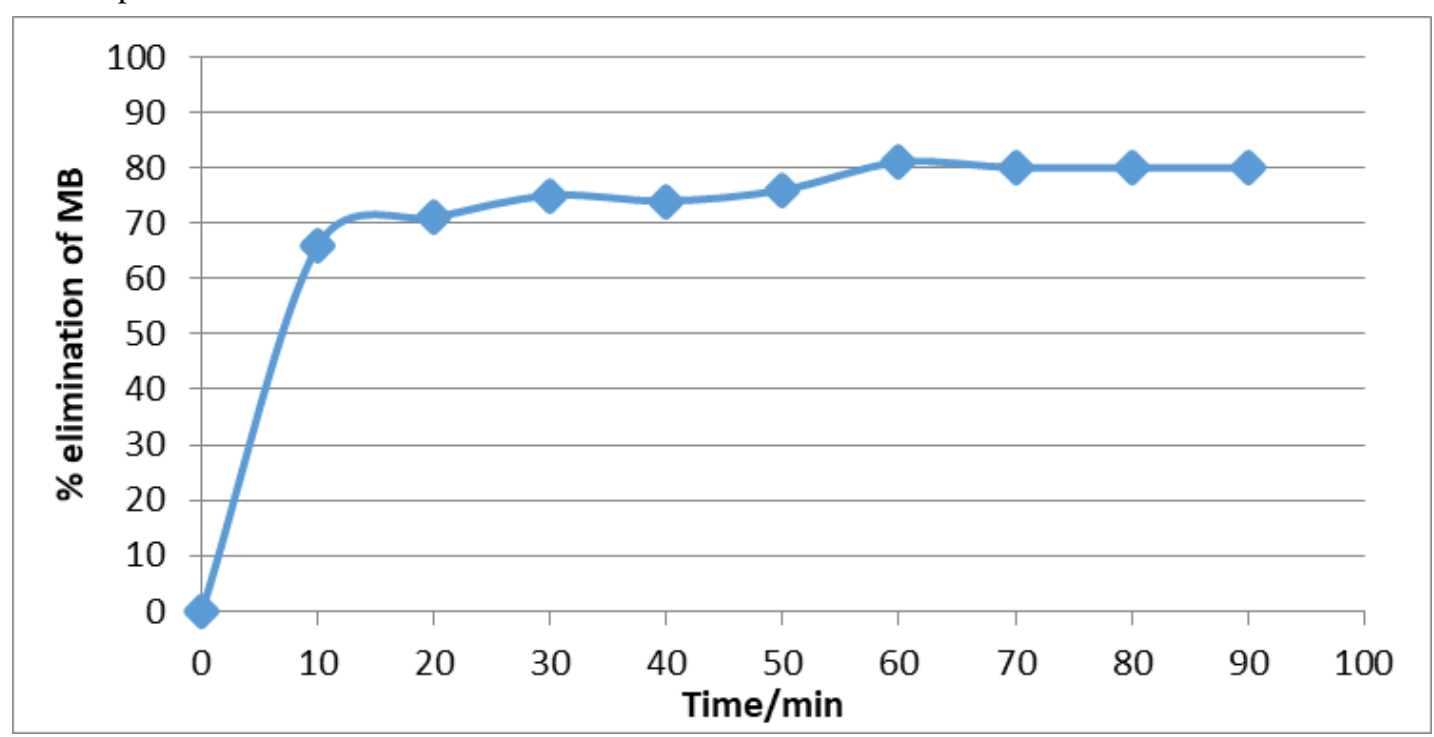

Figure 6. The adsorption kinetics of MB

To determine the time necessary to reach the Time effect of contact MB adsorption equilibrium, experiments were carried out on a $1 \mathrm{~g}$ of the snail shell and a volume of $100 \mathrm{~mL}$ of $\mathrm{MB}$ of concentration equal to $20 \mathrm{mg} / \mathrm{L}$, 
with stirring at $200 \mathrm{rpm}$ at room temperature. Figure 6 illustrates the percentage of changes in $\mathrm{MB}$ removals as a function of time.

The curve in Figure 6 shows that the adsorption kinetics of MB has two distinct stages; the first one is characterized by rapid adsorption during the first 10 minutes, this is due to the adsorption of MB at the surface of adsorbent's particles which can be explained by the high number of activated sites available. In the second stage, the occupation of deep adsorbent sites requires the diffusion of the adsorbed molecule within the microspores of adsorbent. As the recovery rate of the surface increases, accessibility to available sites becomes more and more difficult. Consequently, adsorption speed becomes slower

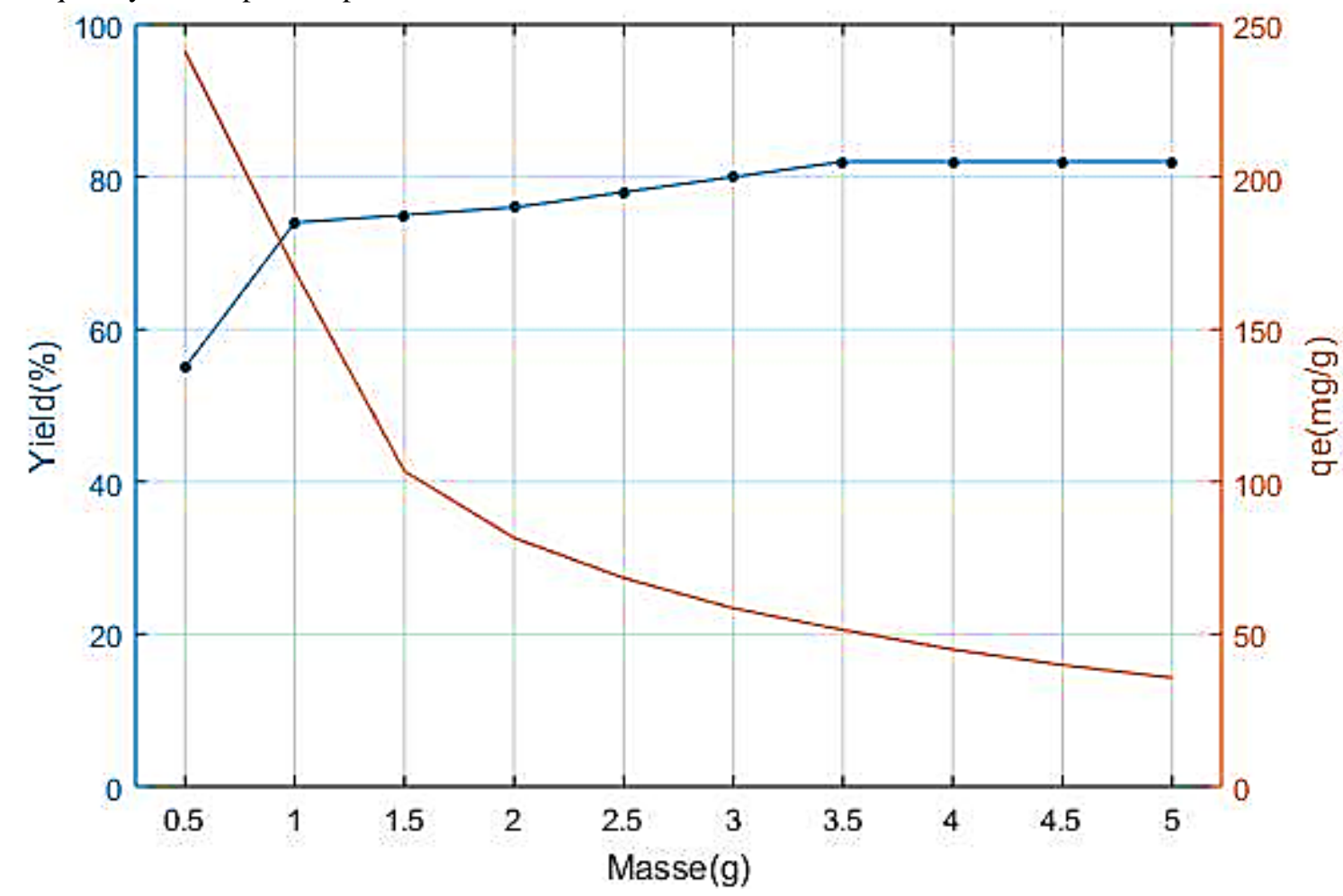

Figure 7. Percentage of elimination of $\mathrm{MB}$ as a function of shell mass
The results of Figure 7 show that when we increase the mass of the adsorbent from $1 \mathrm{~g}$ to $5 \mathrm{~g}$ the percentage of methylene blue removal increases to reach $82 \%$ for $3.5 \mathrm{~g} / 100 \mathrm{~mL}$ of adsorbent. From $3.5 \mathrm{~g}$ of biomass, the percentage of MB elimination is no longer evolving and remains constant. This behavior may be due to the number of adsorption sites, which increases with the amount of adsorbent to a mass of $3.5 \mathrm{~g} / \mathrm{L}$, from which the number of sites becomes stable ${ }^{30}$. These results can be explained as follows; at the beginning of the experiment, there is high availability of both adsorbent biomass and activated until reaching the equilibrium after the majority of active sites were occupied by MB ions.

All these results told us that the equilibrium would be established after 60 minutes. Beyond this time, the adsorbed amount remains substantially constant. Therefore, in the rest of our study, we will work with a 60-minute equilibrium time.

\section{Mass effect}

The mass effect of the adsorbent was studied for $60 \mathrm{~min}$ at room temperature by varying the mass of the snail shell from $0.5 \mathrm{~g}$ to $5 \mathrm{~g}$, on a MB solution $(100 \mathrm{~mL}, 20 \mathrm{mg} / \mathrm{mL})$, stirring speed is at $200 \mathrm{rpm}$ (Figure

7). sites, in which more MB ions can be attached to those sites. At equilibrium, there is no enough available site for MB ions. Therefore the elimination process is no longer evolving and remains constant.

\section{Stirring speed effect}

In order to study the influence of the stirring speed on the adsorption of $\mathrm{MB}$, we set the following operating conditions: volume of MB $100 \mathrm{~mL}$, shell mass $3.5 \mathrm{~g}$ and contact time 60 minutes at room temperature. 


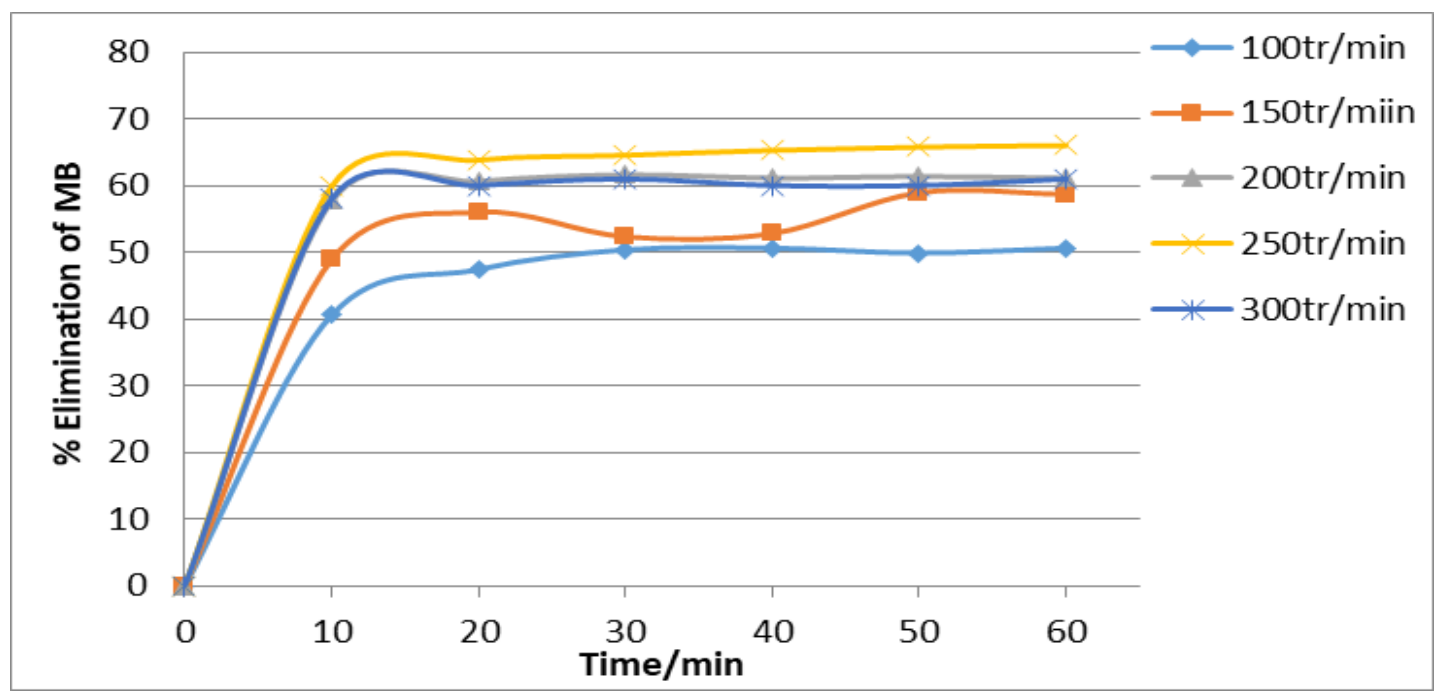

Figure 8. Influence of stirring rate on methylene blue adsorption.

Several agitations were tested as shown in Figure 8. For a low agitation (from 100 to $150 \mathrm{rpm}$ ), the percentage of MB removal is less than $60 \%$. For a moderate agitation ( $250 \mathrm{rpm})$, the adsorption was optimal and reached more than $70 \%$ removal of MB. However, for high agitation $(>=300 \mathrm{rpm})$, the removal rate of $\mathrm{MB}$ is reduced.

\section{Effect of temperature}

In order to obtain an optimal temperature for better adsorption by snail shells, tests have been made using a thermostatic orbital stirrer to maintain the desired value between $15^{\circ} \mathrm{C}$ and $40{ }^{\circ} \mathrm{C}$ ).

The experiments were carried out by adding 1 $\mathrm{g} / \mathrm{L}$ of the shell to the MB solution $(100 \mathrm{~mL})$ and a stirring speed of $250 \mathrm{rpm}$.

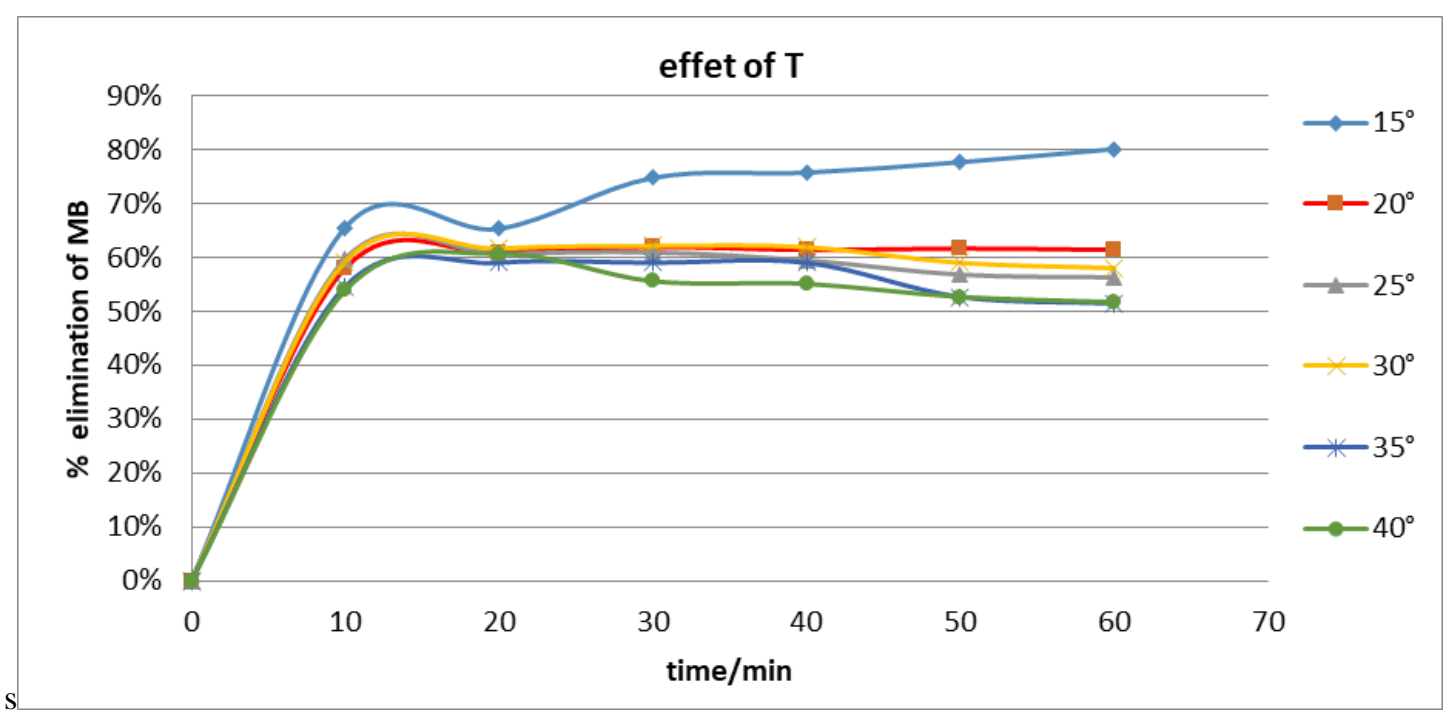

Figure 9. Effect of temperature on the adsorption of the MB by the snail shell

Figure 9 shows that the best results are obtained at a temperature of $15{ }^{\circ} \mathrm{C}$. It can be concluded that the increase in temperature decreases the rate of $\mathrm{MB}$ removal, indicating that the reaction is exothermic.

The reason for the decreasing removal of $\mathrm{MB}$ at high temperature is the increased solubility of $\mathrm{MB}$ ions in the solution at high temperature, which weakens the interaction forces between MB ions and active sites in the shell snail. As a result, MB ions are more difficult to adsorb at high temperatures. Therefore, the low temperatures are favorable for the removal of MB ions by snail shells. Therefore, high temperature hinders the progress of the adsorption phenomenon $^{31}$.

\section{Conclusion}

In this study, a new raw snail shell material was tested, without any treatment (thermal or chemical), by a simple, cost-effective, and quick method to minimize the costs of dye pollution treatments industrial methylene blue on the one hand, and the other hand a recovery of bio-waste used.

The optimal conditions for better elimination can be summarized as follows: temperature of $15^{\circ} \mathrm{C}$, 
agitation of $250 \mathrm{rpm}$, and $3.5 \mathrm{~g}$ of biomass corresponding to the elimination of $82 \%$ of $\mathrm{MB}$.

The results obtained are promising and encouraging to consider a complete study in order to show that the adsorbent chosen for this study is effective and could be used as an economic adsorbent for industrial effluents.

\section{References}

1- I.A.W. Tan, B.H. Hameed, A.L.

Ahmad, Equilibrium and kinetic studies on basic dye adsorption by oil palm fibre activated carbon, Chem. Eng. J, 2007, 127, 111-119.

2- T. Rana, S. Gupta, D. Kumar, S. Sharma, M. Rana, V.S. Rathore, B.M.J. Pereira, Toxic effects of pulp and paper-mill effluents on male reproductive organs and some systemic parameters in rats, Environ. Toxicol Pharmacol, 2004,18, 1, 1-7.

3- K. A. Bennani, B. Mounir, M. Hachkar, M. Bakasse, A.Yaacoubi, Élimination du colorant basique "Bleu de Méthylène" en solution aqueuse par l'argile de Safi, Journal of Water Science, 2010, 23, 4, 375-388.

4- T. Robinson, G. McMullan, R. Marchant et P.Nigam, Remediation of dyes in textile effluent: a critical review on current treatment technologies with a proposed alternative, Bioresour, Technol, 2001, 77, 247-255.

5- A.K. Verma, R.R. Dash, P. Bhunia, A review on chemical coagulation/ flocculation technologies for removal of colour from textile wastewaters, J. Environ. Manag, 2012, 93, 154-168.

6- G. Son, H. Lee, Methylene blue removal by submerged plasma irradiation system in the presence of persulfate, Environ. Sci. Pollut. Res., 2016, 23, 15651-15656.

7- S. Zinadini, A.A. Zinatizadeh, M. Rahimi, V. Vatanpour, H. Zangeneh, M. Beygzadeh, Novel high flux antifouling nanofiltration membranes for dye removal containing carboxymethyl chitosan coated $\mathrm{Fe} 3 \mathrm{O} 4$ nanoparticles, Desalination, 2014, 349, 145-154.

8- Ö. Kerkez-Kuyumcu, E. Kibar, K. Dayı glu, F. Gedik, A.N. Akın, S. Özkara-Aydıno_glu, A comparative study for removal of different dyes over $\mathrm{M} / \mathrm{TiO} 2(\mathrm{M}=\mathrm{Cu}, \mathrm{Ni} \mathrm{Co}, \mathrm{Fe}, \mathrm{Mn}$ and $\mathrm{Cr}$ ) photocatalysts under visible light irradiation, $\mathrm{J}$. Photochem. Photobiol. A Chem, 2015, 311, 176-185.

9- I. Khouni, B. Marrot, R.B. Amar, Treatment of reconstituted textile wastewater containing a reactive dye in an aerobic sequencing batch reactor using a novel bacterial consortium , Sep. Purif. Technol, 2012, 87, 110-119.

10- N. Fayoud, S. Alami Younssi, S. Tahiri, A. Albizane, Kinetic and thermodynamic study of the adsorption of methylene blue on wood ashes, J. Mater. Environ. Sci, 2015, 6, 11, 3295-3306.

11- E. El-Qada, S. Allen et G. Walker, Chemical Engineering, 2008, 142, 1.

12- L. Kadiri, A. Ouass, Y. Essaadaoui, E. Rifi and A. Lebkiri, Coriandrum sativum seeds as a green low cost biosorbent for methylene blue dye removal from aqueous solution: spectroscopic, kinetic and thermodynamic

12- studies, Mediterr.J.Chem., 2018, 7(3), 204-216.

13- A.A. Azzaz, S. Jellali, A.A. Assadi,

L. Bousselmi, Chemical treatment of orange tree sawdust for a cationic dye enhancement removal from aqueous solutions: kinetic, equilibrium and thermodynamic studies, Desalin. Water. Treat, 2016, 57, 22107-22119.

14- S. S. Salih, T. K. Ghosh, Preparation and Characterization of Chitosan-Coated Diatomaceous Earth for Hexavalent Chromium Removal, Environmental Processes, 2018, 5, 23-39.

15- S. S. Salih, T. K. Ghosh, Preparation and characterization of bioadsorbent beads for chromium and zinc ions adsorption, Co-gent Environmental Science 3, 2017, 1, 1401577.

16- S. S. Salih, T. K. Ghosh, Adsorption of Zn(II) ions by chitosan coated diatomaceous earth, International journal of biological macromolecules, 2018, 106, 602-610.

17- S.C. Wu, H.C. Hsu, S.K. Hsu, C.P. Tseng, W.F. Ho, Preparation and characterization of hydroxyapatite synthesized from oyster shell powders, Advanced Powder Technology, 2017, 28, 4, 1154-1158. DOI:

10.1016/j.apt.2017.02.001.

18- S. Arulvel, A. Elayaperumal, M.S. Jagatheeshwaran, Electroless nickelphosphorus coating on crab shell particles and its Characterization, Journal of Solid State Chemistry, 2017, 248, 87-95.

19- Lorenz Anthony T. Fernandoa, Myra Ruth S. Pobletea, Aileen Grace M. Ongkikoa, Leslie Joy L. Diaza, Chitine extraction and synthesis of chitin-based polymer films from philippine blue swimming crab (Portunus pelagicus) Shells, Procedia Chem., 2016, 19, 462-468.

20- K. Z. Elwakeel, A. M. Elgarahy, S. H. Mohammad, Use of beach Bivalve shells located at Port Said coast (Egypt) as a green approach for methylene blue Removal, Eng., 2017, 5, 578-587.

21- H. Essabir, M. Ouadi Bensalah, D. Rodrigue, R. Bouhfid, Abou el kacem Qaiss, A comparison between bio- and mineral calcium carbonate on the properties of polypropylene composites, Construction and Building Materials,2017, 134, 549-555.

22- A. Singh, K.M. Purohit, Chemical synthesis, characterization and bioactivity evaluation of hydroxyapatite prepared from garden snail 
(Helix aspersa), J. Bioproc. Biotech,2011, 1, 104-109

23- A.O. Nurudeen, D.A. Yekini, Snail shell as coagulant aid in the alum precipitation of malachite green from aqua system, J. Hazard. Mater, 2009,164, 1496-1502.

24- H. Zhou, M. Yang, M. Zhang, S. Hou, S. Kong, L. Yang, L. Deng, Preparation of Chinese mystery snail shells derived hydroxyapatite with different morphology using condensed phosphate sources, Ceram. Int, 2016, 42, 16671-16676.

25- G.S. Kumar, L. Sathish, R. Govindan, E.K. Girija, Utilization of snail shells to synthesise hydroxyapatite nanorods for orthopedic applications, RSC Adv, 2015, 5, 39544-39548.

26- M.A. Dasgupta, K.M. Purohit, Synthesis of nano-crystalline hydroxyapatite from dead snail shells for biological implantation, Trends Biomater. Artif. Organs, 2 011, 25, 101-106.

27- M. Auta, B.H. Hameed, Chitosan-clay composite as highly effective and low-cost
Adsorbent for batch and fixed-bed adsorption of methylene blue, Chemical Engineering Journal, 2014, 237, 352-361.

28- I.J. Macha, L.S. Ozyegin, J. Chou, R. Samur, F.N. Oktar, B. Ben-Nissan, An alternative synthesis method for di calcium phosphate (monetite) powders from Mediterranean mussel (mytilus galloprovincialis) shells, J. Aus. Ceram. Soc., 2013, 49, 122-128.

29- D. Cuenca-Solana, I. Guti_errez-Zugasti, M.R. Gonzalez-Morales, Use-wear analysis: An optimal methodology for the study of shell tools, Quaternary International, 2017, 427, 192-200.

30- K. Belgin, T. Fatma, D. Hakan, J. İlknur, Int. Environmental Application \& Science, 2008, Vol. 3, 5, 373-380.

31- A. Aarfane, A. Salhi, M. El Krati, S. Tahiri, M. Monkade, K. LhadiE, M. Bensitel, J. Mater. Environ. Sci, 2014, 5, 1927-1939. 